On the metastable level in $\mathrm{Ni}$-like ions

E. Träbert, P. Beiersdorfer, G. V. Brown, S.

Terracol, U. I. Safronova

September 27, 2004

Nucelar Instruments and Methods in Physics Research B 
This document was prepared as an account of work sponsored by an agency of the United States Government. Neither the United States Government nor the University of California nor any of their employees, makes any warranty, express or implied, or assumes any legal liability or responsibility for the accuracy, completeness, or usefulness of any information, apparatus, product, or process disclosed, or represents that its use would not infringe privately owned rights. Reference herein to any specific commercial product, process, or service by trade name, trademark, manufacturer, or otherwise, does not necessarily constitute or imply its endorsement, recommendation, or favoring by the United States Government or the University of California. The views and opinions of authors expressed herein do not necessarily state or reflect those of the United States Government or the University of California, and shall not be used for advertising or product endorsement purposes. 


\title{
On the metastable level in Ni-like ions
}

\author{
E. Träbert ${ }^{*, a, b}$, P. Beiersdorfer ${ }^{\mathrm{a}}$, G. V. Brown ${ }^{\mathrm{c}}$, S. Terracol ${ }^{\mathrm{a}}$, \\ U. I. Safronova ${ }^{\text {d }}$ \\ ${ }^{a}$ Physics and Advanced Technologies, Lawrence Livermore National Laboratory, \\ Livermore, CA 94550-9234, U.S.A. \\ ${ }^{\mathrm{b}}$ Fakultät für Physik und Astronomie, Ruhr-Universität Bochum, D-44780 \\ Bochum, Germany \\ ${ }^{c}$ Goddard Space Flight Center, Greenbelt, MD 20771, U.S.A. \\ ${ }^{\mathrm{d}}$ University of Nevada Reno, Reno, NV 89557, U.S.A.
}

\begin{abstract}
The lowest excited level in Ni-like ions, $3 \mathrm{~d}^{9} 4 \mathrm{~s}{ }^{3} \mathrm{D}_{3}$, decays only via a magnetic octupole (M3) decay. We present calculated values of transition wavelengths and rates for ions with $30 \leq \mathrm{Z} \leq 100$. We have observed this line in $\mathrm{Xe}^{26+}$, using the Livermore EBIT-I electron beam ion trap and a microcalorimeter, as well as a highresolution flat-field grating spectrometer.
\end{abstract}

Key words: X-ray spectra, Atomic lifetimes, Ion trapping PACS: 32.30.Rj, 31.15.Ar, 32.70.Cs

Long-lived excited levels are of interest for the detailed understanding of atomic structure and high-multipole order decay processes. They also are important for the modeling of charge state distributions and charge balances in a variety of plasmas. For example, there is the lowest excited level in Ni-like ions, $3 \mathrm{~d}^{9} 4 \mathrm{~s}^{3} \mathrm{D}_{3}$, that can decay to the ground state only by a magnetic octupole (M3) transition. This level has been treated in a number of calculations of $\mathrm{Ni}$-like ions (see, for example, [1] for results on seven selected ions). The sole observation of this M3 decay so far has been in Ni-like $\mathrm{Th}^{62+}$ and $\mathrm{U}^{64+}$, in one of Livermore's electron beam ion traps [2]. These measurements showed that the corresponding transition sits amidst a plethora of electric-dipole forbidden transitions, i.e. M1 and $\mathrm{E} 24 \mathrm{~s} \rightarrow 3 \mathrm{~d}$ decays in Ni-like ions and in ions of neighbouring charge states. Electric-dipole forbidden transitions thus dominate a large region of the M-shell x-ray emission of Ni-like and near Ni-like ions. We

*

Email address: trabert1@llnl.gov (E. Träbert). 
are now using the Livermore EBIT-I electron beam ion trap [3] in a search for this particular decay in the mid-Z Ni-like ion $\mathrm{Xe}^{26+}$.

In addition, we have calculated by many-body perturbation theory (MBPT) the wavelengths and transition rates of the M3 decay in the ions of the $\mathrm{Ni}$ isoelectronic sequence $(Z=30$ to $Z=100)$ (Table 1$)$. These MBPT calculations are similar to those on the lower-multipole order transitions in the $\mathrm{Ni}$ isoelectronic sequence $[4,5]$. The predicted ${ }^{3} \mathrm{D}_{3}$ level lifetime ranges from 50 years $(Z=30)$ to $3 \mu \mathrm{s}(Z=100)$. Neither of these is easily measured. For an element in the middle of the periodic table, $\mathrm{Xe}(\mathrm{Z}=54)$, the MBPT calculation predicts transition wavelengths near $21 \AA$ (transition energy near $600 \mathrm{eV}$ ) and a ${ }^{3} \mathrm{D}_{3}$ level lifetime near $18 \mathrm{~ms}$. This is exceptionally long for a highly charged ion, and it explains why such an individual level may be of importance in spectral modeling. However, it is also in the lifetime range that has been successfully studied at electron beam ion traps, in particular the ones at Livermore (see, for example, $[6,7])$.

Besides the $3 \mathrm{~d}^{10}-3 \mathrm{~d}^{9} 4 \mathrm{~s}$ transitions of interest, there also are decays of $4 \mathrm{p}, 4 \mathrm{~d}$, and $4 \mathrm{f}$ levels of the same ion, plus those of levels of similar configurations in the neighbouring charge state ions. None of these levels, however, is expected to be as long-lived as is the aforementioned level of primary interest in the Ni-like ion. In a given ion of moderately high charge, levels that decay by E1 transitions usually feature lifetimes in the picosecond range, while the levels that decay predominantly by M1 or E2 transitions may have lifetimes in the nanosecond or microsecond range. Moreover, $3 \mathrm{~d}^{9} 4 \mathrm{~d}$ levels cannot decay easily towards $3 \mathrm{~d}^{10}$ levels; their predominant decay branch leads to $3 \mathrm{~d}^{9} 4 \mathrm{p}$ levels, and the associated radiation is in a range of much longer wavelengths.

Unwanted complexity of the spectra can be reduced by preventing the production of ions in charge states different from the one of primary interest. In an electron beam ion trap, this goal can be approached by making the charge state of interest the highest one that can be reached. We used an electron beam energy of $1450 \mathrm{eV}$ which is sufficient to ionize Cu-like ions of Xe and thus make Ni-like ions, but which is not sufficient to ionize the latter. Therefore only ions with a filled $3 \mathrm{~d}$ shell ground configuration are produced, and for most of these the strongest line emission is expected for $4-4$ transitions, again far from our soft-x-ray observation range.

Spectra recorded with a multi-pixel cryogenic ( $\mathrm{T}=59 \mathrm{mK}$ ) XRS microcalorimeter (built by Goddard Space Flight Center) [8,9] are, indeed, dominated by line groups (not individually resolved at present) that we associate with the $3 \mathrm{~d}^{9} 4 \mathrm{~s}$, $4 \mathrm{p}$, and $4 \mathrm{f}$ level decays of $\mathrm{Xe}^{26+}$ ions. Fig. 1 (top) shows a combination of the signals from 13 pixels, with a combined area of about $6 \mathrm{~mm}^{2}$. The narrowest structure has a half width of about $12 \mathrm{eV}$ which is wider than the nominal line width of the device (about $7 \mathrm{eV}$ ) and probably relates to a number of 
unresolved lines.

Higher than the apparent resolving power $\mathrm{E} / \Delta \mathrm{E} \approx 50$ of the microcalorimeter is the resolving power of a grazing incidence spectrometer. We used a flatfield grating spectrometer that is based on a variable line spacing grating of $\mathrm{R}=44.3 \mathrm{~m}$ (mean groove density $2400 \ell / \mathrm{mm}$ ) and that has a cryogenic CCD camera as a detector [10]. This instrument yielded spectra with a resolving power $\lambda / \Delta \lambda \approx 800$, covering a wavelength range of about $7 \AA$ at a mean wavelength of about $20 \AA$. The spectra were calibrated with well known lines of He- and H-like oxygen. A section of such a spectrum is shown in Fig. 2.

In Fig. 2 we identify the lines from the $\Delta n=1$ decays of the four $\mathrm{Xe}^{26+} 3 \mathrm{~d}^{9} 4 \mathrm{~s}$ levels, and one of the oxygen calibration lines. The Xe M3 line of primary interest appears relatively weakly, because the long-lived upper level is not only excited, but also collisionally quenched by the electron beam. Because of the long level lifetime, it nevertheless survives as the strongest line when the electron beam is switched off, as is shown in Fig. 1.

In the XRS microcalorimeter, each signal is time stamped by the event mode recording system, and synchronization with the cyclical excitation and trapping operations is feasible. This feature opens the possibility of time resolved observations, synchronized with the cyclical operation of the electron beam ion trap. As long as the electron beam in the electron beam ion trap is switched on, ions are charged up, and a plenitude of x-ray lines can be observed. When the electron beam is switched off, the trap with its $3 \mathrm{~T}$ magnetic field and the drift tube voltages continues to hold ions, as any Penning trap does, in the so-called 'magnetic trapping mode' [11].

For the present measurements, the trap cycle included about $50 \mathrm{~ms}$ for breeding the desired charge state (electron beam on), $60 \mathrm{~ms}$ for the observation of delayed emission (electron beam off), plus time for dumping the ion cloud before restarting the cycle. The delayed emission from the trapped ion cloud, without fresh excitation by the electron beam, shows only very few lines (Fig. 1 bottom). Among these are weak lines from highly charged oxygen ions after charge exchange with the residual gas. A single Xe line dominates the delayed emission spectrum after the electron beam has been switched off. (This approach corresponds to the study of long-lived level decays by beam-foil spectroscopy [12], where the advantage of time resolution can outweigh limited spectral resolution and other factors.)

Time-sorting measurements are in progress. The predictions for the M3 transition rate ([13] and our own calculations using the Grant code [14] or MBPT) are listed in Table 2.

In conclusion, we have presented observations of the M3 transition in Nilike Xe, including a measurement of its transition energy. This sets the stage 
for measuring the transition probability of the magnetic octupole decay in a Ni-like heavy ion in the middle of the periodic table of the elements. Such measurements complement and extend the earlier identification of the M3 decay in $\mathrm{Th}^{62+}$ and $\mathrm{U}^{64+}[2]$, and should further the plasma modeling efforts by providing calibration points for calculations that are the base for radiativecollisional models. The experiment has demonstrated the unique capabilities of a combination of the EBIT-I electron beam ion trap with high spectral resolution available from a flat-field grating EUV spectrometer and with the time resolution available from the XRS microcalorimeter. Evidently, such a combination is superior to any individual experimental approach.

The work at the University of California Lawrence Livermore National Laboratory was performed under the auspices of the US Department of Energy under Contract No. W-7405-Eng-48. ET acknowledges travel support from the German Research Association (DFG).

\section{References}

[1] E. Biémont, J. Phys. B: At. Mol. Opt. Phys. 30 (1977) 4207

[2] P. Beiersdorfer, A. L. Osterheld, J. Scofield, B. Wargelin, and R. E. Marrs, Phys. Rev. Lett. 67 (1991) 2272

[3] M. A. Levine, R. E. Marrs, J. N. Bardsley, P. Beiersdorfer, C. L. Bennett, M. H. Chen, T. Cowan, D. Dietrich, J. R. Henderson, D. A. Knapp, A. Osterheld, B. M. Penetrante, M. B. Schneider, and J. H. Scofield, Nucl. Instrum. Meth. B 43 (1989) 431

[4] U. I. Safronova, W. R. Johnson, J. R. Albritton, Phys. Rev. A 62 (2000) 052505

[5] S. M. Hamasha, A. S. Shlyaptseva, U. I. Safronova, Can. J. Phys. 82 (2004) 331

[6] Träbert, E., Beiersdorfer, P., Utter, S.B., Brown, G.V., Harris, C.L., Neill, P.A., Savin, D.W., and Smith, A.J., Astrophys. J. 541 (2000) 506

[7] Träbert, E., Beiersdorfer, P., Gwinner, G., Pinnington, E. H., and Wolf, A., Phys. Rev. A 66 (2002) 052507

[8] F. S. Porter, M. D. Audley, P. Beiersdorfer, K. R. Boyce, R. P. Brekosky, G. V. Brown, K. C. Gendreau, J. Gygax, S. Kahn, R. L. Kelley, C. K. Stahle, A. E. Szymkowiak, Proc. SPIE 4140 (2000) 407

[9] F. S. Porter, G. V. Brown, K. R. Boyce, R. L. Kelley, C. A. Kilbourne, P. Beiersdorfer, H. Chen, S. Terracol, S. M. Kahn, A. E. Szymkowiak, Rev. Sci. Instrum. 75 (2004) (in press)

[10] P. Beiersdorfer, E. W. Magee, E. Träbert, H. Chen, J. K. Lepson, and M.-F. Gu, Rev. Sci. Instrum. 75 (2004) (in press) 
[11] P. Beiersdorfer, L. Schweikhard, J. Crespo López-Urrutia, and K. Widmann, Rev. Sci. Instrum. 67 (1996) 3818

[12] E. Träbert, P. H. Heckmann, R. Hutton, I. Martinson, J. Opt. Soc. Am. B 5 (1988) 2173

[13] J. H. Scofield (private communication)

[14] I. P. Grant, in Methods in Computational Chemistry, Vol. 2 (ed. S. Wilson), Plenum Press, New York, 1988, p. 1 


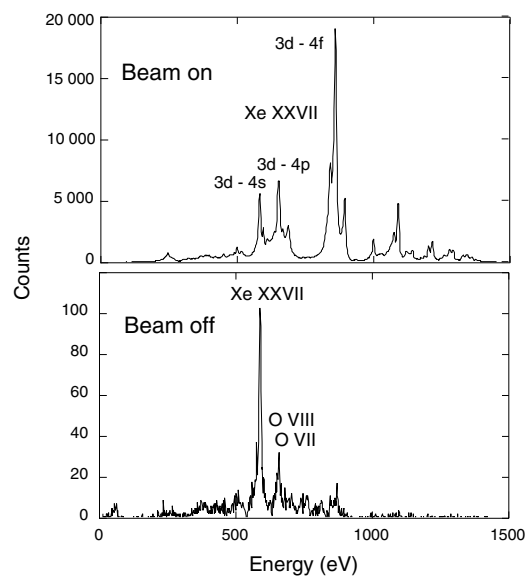

Fig. 1. Time-resolved soft-x-ray data obtained with the XRS microcalorimeter at an electron beam energy of $1450 \mathrm{eV}$. Top: steady state with electron beam on; bottom: after switching the electron beam off. The spectrum recorded with the electron beam on is dominated by the $3 \mathrm{~d}^{10}-3 \mathrm{~d}^{9} 4 \ell$ transitions of $\mathrm{Xe}^{26+}$. Of the progression of upper levels $4 \mathrm{~s}-4 \mathrm{p}-4 \mathrm{~d}-4 \mathrm{f}$, the $4 \mathrm{~d}$ configuration does not contribute, because its levels can decay only within the $n=4$ shell.

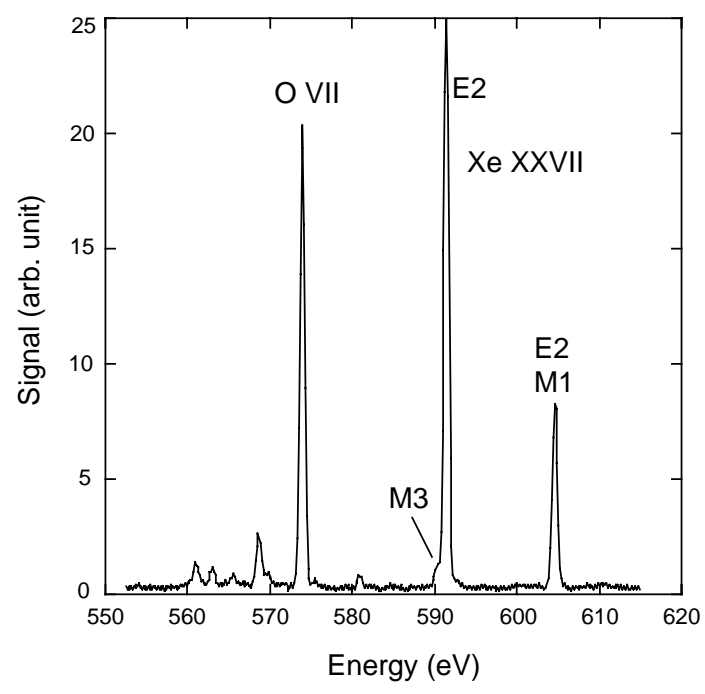

Fig. 2. Detail of a soft-X-ray spectrum recorded with the flat-field spectrometer. Xe is being injected into the trap, but some of the strongest oxygen lines persist from calibration runs with $\mathrm{CO}_{2}$ injection. The four soft-X-ray decays of $\mathrm{Xe}^{26+} 3 \mathrm{~d}^{9} 4$ s levels are marked by their multipole orders. 
Table 1

Predicted values for the $3 \mathrm{~d}-4 \mathrm{~s}$ transition wavelength and M3 decay rate of the $3 \mathrm{~d}^{9} 4 \mathrm{~s}^{3} \mathrm{D}_{3}$ level in Ni-like ions. The notation aE-x means a $10^{-x}$.

\begin{tabular}{rrrrrr}
\hline $\mathrm{Z}$ & M3 Rate $\left(\mathrm{s}^{-1}\right)$ & Wavelength $(A)$ & $\mathrm{Z}$ & M3 rate $\left(\mathrm{s}^{-1}\right)$ & Wavelength $(A)$ \\
\hline 30 & $0.6958 \mathrm{E}-09$ & 1961.211 & 66 & $0.1539 \mathrm{E}+04$ & 10.991 \\
31 & $0.3787 \mathrm{E}-06$ & 776.737 & 67 & $0.1938 \mathrm{E}+04$ & 10.513 \\
32 & $0.9149 \mathrm{E}-04$ & 460.514 & 68 & $0.2487 \mathrm{E}+04$ & 10.069 \\
33 & $0.4933 \mathrm{E}-06$ & 315.603 & 69 & $0.2989 \mathrm{E}+04$ & 9.653 \\
34 & $0.3279 \mathrm{E}-04$ & 233.980 & 70 & $0.3701 \mathrm{E}+04$ & 9.265 \\
35 & $0.2801 \mathrm{E}-03$ & 182.268 & 71 & $0.4553 \mathrm{E}+04$ & 8.901 \\
36 & $0.1100 \mathrm{E}-02$ & 146.934 & 72 & $0.5575 \mathrm{E}+04$ & 8.559 \\
37 & $0.3526 \mathrm{E}-02$ & 121.399 & 73 & $0.6784 \mathrm{E}+04$ & 8.239 \\
38 & $0.1060 \mathrm{E}-01$ & 102.476 & 74 & $0.8221 \mathrm{E}+04$ & 7.938 \\
39 & $0.3514 \mathrm{E}-01$ & 87.796 & 75 & $0.9917 \mathrm{E}+04$ & 7.655 \\
40 & $0.4422 \mathrm{E}-01$ & 76.198 & 76 & $0.1191 \mathrm{E}+05$ & 7.388 \\
41 & $0.1081 \mathrm{E}+00$ & 66.866 & 77 & $0.1425 \mathrm{E}+05$ & 7.136 \\
42 & $0.2230 \mathrm{E}+00$ & 59.204 & 78 & $0.1698 \mathrm{E}+05$ & 6.898 \\
43 & $0.4036 \mathrm{E}+00$ & 52.850 & 79 & $0.2015 \mathrm{E}+05$ & 6.673 \\
44 & $0.7262 \mathrm{E}+00$ & 47.497 & 80 & $0.2382 \mathrm{E}+05$ & 6.460 \\
45 & $0.1339 \mathrm{E}+01$ & 42.956 & 81 & $0.2805 \mathrm{E}+05$ & 6.258 \\
46 & $0.2036 \mathrm{E}+01$ & 39.051 & 82 & $0.3292 \mathrm{E}+05$ & 6.068 \\
47 & $0.3340 \mathrm{E}+01$ & 35.677 & 83 & $0.3849 \mathrm{E}+05$ & 5.886 \\
48 & $0.5253 \mathrm{E}+01$ & 32.738 & 84 & $0.4480 \mathrm{E}+05$ & 5.714 \\
49 & $0.7923 \mathrm{E}+01$ & 30.160 & 85 & $0.5266 \mathrm{E}+05$ & 5.551 \\
50 & $0.1236 \mathrm{E}+02$ & 27.885 & 86 & $0.6057 \mathrm{E}+05$ & 5.396 \\
51 & $0.1769 \mathrm{E}+02$ & 25.863 & 87 & $0.6987 \mathrm{E}+05$ & 5.248 \\
52 & $0.2615 \mathrm{E}+02$ & 24.076 & 88 & $0.8040 \mathrm{E}+05$ & 5.108 \\
53 & $0.3780 \mathrm{E}+02$ & 22.464 & 89 & $0.9223 \mathrm{E}+05$ & 4.974 \\
54 & $0.5371 \mathrm{E}+02$ & 21.015 & 90 & $0.1055 \mathrm{E}+06$ & 4.847 \\
55 & $0.7551 \mathrm{E}+02$ & 19.708 & 91 & $0.1203 \mathrm{E}+06$ & 4.725 \\
56 & $0.1044 \mathrm{E}+03$ & 18.524 & 92 & $0.1368 \mathrm{E}+06$ & 4.609 \\
57 & $0.1403 \mathrm{E}+03$ & 17.448 & 93 & $0.1561 \mathrm{E}+06$ & 4.499 \\
58 & $0.1901 \mathrm{E}+03$ & 16.467 & 94 & $0.1758 \mathrm{E}+06$ & 4.394 \\
59 & $0.2545 \mathrm{E}+03$ & 15.570 & 95 & $0.1981 \mathrm{E}+06$ & 4.293 \\
60 & $0.3368 \mathrm{E}+03$ & 14.747 & 96 & $0.2227 \mathrm{E}+06$ & 4.197 \\
61 & $0.4424 \mathrm{E}+03$ & 13.991 & 97 & $0.2498 \mathrm{E}+06$ & 4.018 \\
62 & $0.5762 \mathrm{E}+03$ & 13.294 & 98 & $0.2793 \mathrm{E}+06$ & 3.934 \\
63 & $0.7440 \mathrm{E}+03$ & 12.651 & 99 & $0.3114 \mathrm{E}+06$ & 3.855 \\
64 & $0.9549 \mathrm{E}+03$ & 12.055 & 100 & $0.3462 \mathrm{E}+06$ & \\
65 & $0.1213 \mathrm{E}+04$ & 11.504 & & & \\
\hline & & & & & \\
\hline
\end{tabular}


Table 2

Transition wavelength and M3 decay rate of the $3 \mathrm{~d}^{9} 4 \mathrm{~s}^{3} \mathrm{D}_{3}$ level in $\mathrm{Xe}^{26+}$.

\begin{tabular}{ccl}
\hline Wavelength $(\AA)$ & Decay rate $\left(\mathrm{s}^{-1}\right)$ & Reference \\
\hline Calculation & & \\
21.103 & 61.1 & Scofield [13] \\
21.054 & 71 & Grant code calculation [14] (this work) \\
21.015 & 53.71 & MBPT calculation (this work) \\
Experiment & & \\
$21.000 \pm 0.002$ & & This work \\
\hline
\end{tabular}

